\title{
ARTICLE
}

\section{Silver confined within zeolite EMT nanoparticles: preparation and antibacterial properties}

\author{
B. Dong,${ }^{a, b}$ S. Belkhair, ${ }^{c}$ M. Zarrour,${ }^{a}$ L. Fisher, ${ }^{c}$ J. Verran,${ }^{c}$ L. Tosheva, ${ }^{* c}$ R. Retoux,${ }^{\mathrm{d}}$ J. - \\ P. Gilson ${ }^{a}$ and S. Mintova*a
}

Received ooth January 2012, Accepted ooth January 2012

DOI: $10.1039 /$ xoxxooooox

www.rsc.org/

\begin{abstract}
The preparation of pure zeolite nanocrystals (EMT-type framework) and their silver ionexchanged $\left(\mathrm{Ag}^{+}\right.$-EMT) and reduced silver $\left(\mathrm{Ag}^{0}\right.$-EMT) forms is reported. The template-free zeolite nanocrystals are stabilized in water suspensions and used directly for silver ionexchange and subsequent chemical reduction under microwave irradiation. The high porosity, low $\mathrm{Si} / \mathrm{Al}$ ratio, high concentration of sodium and ultrasmall crystal size of the EMT-type zeolite permitted the introduction of high amount of silver using short ion-exchange times in the range 2-6 h. The killing efficacy of pure EMT, $\mathrm{Ag}^{+}$-EMT and $\mathrm{Ag}^{0}$-EMT against Escherichia Coli was studied semi-quantitatively. Antibacterial activity increased with increasing $\mathrm{Ag}$ content for both type samples $\left(\mathrm{Ag}^{+}\right.$-EMT and $\mathrm{Ag}^{0}$-EMT). The $\mathrm{Ag}^{0}$-EMT samples show slightly enhanced antimicrobial efficacy compared to that of $\mathrm{Ag}^{+}$-EMT, however, the differences are not substantial and the preparation of $\mathrm{Ag}$ nanoparticles is not viable considering the complexity of preparation steps.
\end{abstract}

\section{Introduction}

The introduction of antimicrobials to a vast range of materials, including medical devices, food packaging, clothing and toiletries, for purposes of reducing infection or deterioration, or for hygienic and mechanical reasons has been widely researched. Antibacterial inorganic materials present important advantages over traditionally used organic agents due to their chemical and thermal stability allowing for flexible processing during preparation of nanocomposites, alloys, coatings and other complex structures. ${ }^{1,2}$ Amongst them, silver, with its broad spectrum of antimicrobial properties, has become one of the most intensively studied systems. ${ }^{3}$ There have been a certain degree of controversy in mechanistic studies of silver toxicity because of the huge variations in antibacterial tests / silver systems used. ${ }^{4}$ The antibacterial effect of silver has been associated with the release of silver ions in aqueous solutions causing plasmolysis after entering the bacterial cell and partial disruption of the cytoplasmic membrane and affecting the DNA replication ability. ${ }^{5}$ Direct damage of the bacterial cell walls and accumulation of silver in the membrane have been demonstrated by Sondi and Salopek-Sondi. ${ }^{6}$ The bactericidal effect of silver nanoparticles have also been found dependent on the nanoparticle size. ${ }^{7}$ Silver nanoparticles with sizes below $10 \mathrm{~nm}$ were found to directly interact with bacterial cells. Further, it has been demonstrated that activity of silver nanoparticles was due to the aerobic release of silver ions and that $\mathrm{Ag}^{0}$ did not have any bactericidal properties. ${ }^{8-10}$

In many cases, slow release of silver ions over long periods of time is required to ensure sustainable antibacterial efficacy conforming to the requirements of the specific application. For long-term antibacterial applications, silver is usually incorporated into matrices, such as zeolites. Zeolites are microporous crystalline aluminosilicates, composed of $\mathrm{TO}_{4}$ tetrahedra $(\mathrm{T}=\mathrm{Si}$ or $\mathrm{Al})$ linked to each other by oxygen ions. Each $\mathrm{AlO}_{4}$ tetrahedron brings a net negative charge, which is balanced by a cation. The channels or interconnected voids of the framework are occupied by cations, which can readily be exchanged by silver via ion-exchange post synthesis treatment. Recently, a procedure to optimise the ion-exchange conditions to yield a high silver loading in the zeolite was reported. ${ }^{11}$ In aqueous medium, silver ions can be released and act as an antimicrobial. ${ }^{12}$ The stabilisation of $\mathrm{Ag}$ within the zeolite matrix has resulted in enhanced antifungal activity in comparison with free Ag ions. ${ }^{13}$ The antibacterial properties of Ag-zeolites have been found to depend on various factors such as the physical form of the zeolite host (e.g., powder, granules or pellets), ${ }^{14}$ the zeolite pore architecture ${ }^{15}$ and the silver form $\left(\mathrm{Ag}^{+}\right.$or $\left.\mathrm{Ag}^{0}\right) .{ }^{16}$ Although several studies have reported the antibacterial properties of Ag-zeolites following reduction of the ion-exchanged silver, ${ }^{17,18}$ a direct comparison of the antibacterial efficacy of $\mathrm{Ag}^{+}$-zeolites and $\mathrm{Ag}^{0}$-zeolites has not been reported. Also, the antibacterial properties of nanosized Ag-zeolites stabilized in aqueous suspensions have not been studied before.

In the present work, silver was ion-exchanged at different levels within a zeolite and the antibacterial properties of the materials obtained before and after silver reduction were directly compared. The host material employed was selected to be ultrasmall EMT-type zeolite (diameter of 10 to $20 \mathrm{~nm}$ ) stabilized in water suspesnions, which was synthesized in the absence of organic template. ${ }^{19}$ The template-free EMT type 
zeolite crystals did not require high temperature treatment to open up their pore structure and were used directly for introduction of silver via ion-exchange. The low $\mathrm{Si} / \mathrm{Al}$ ratio, high porosity and large pore size makes the EMT zeolite an ideal host for introduction of silver ions, and following subsequent reduction, confined silver nanoparticles.

\section{Experimental}

\section{Synthesis of silver-EMT zeolites}

A template-free $\mathrm{Na}_{2} \mathrm{O}-\mathrm{Al}_{2} \mathrm{O}_{3}-\mathrm{SiO}_{2}-\mathrm{H}_{2} \mathrm{O}$ precursor system (Narich) was employed for the preparation of the nanosized EMTtype zeolite. ${ }^{19}$ Ultrasmall hexagonal EMT nanocrystals (diameter of 10 to $20 \mathrm{~nm}$ ) were obtained at $30{ }^{\circ} \mathrm{C}$ for $36 \mathrm{~h}$ without using any organic template. The EMT zeolite formed stable colloidal suspensions and the silver ion exchange was performed in aqueous medium to avoid agglomeration. The ion-exchange process was performed as follows: $20 \mathrm{ml}$ silver perchlorate solutions with concentration of $0.05 \mathrm{M}$ were added to three dispersed EMT zeolite suspensions (7.5 wt. \%, $12 \mathrm{ml}$ ) and kept for $2 \mathrm{~h}, 4 \mathrm{~h}$ and $6 \mathrm{~h}$. The ion-exchanged samples were purified three times via high-speed centrifugation and redispersed in water. The silver nanoparticles (Ag NPs) in the EMT zeolite suspensions $(2 \mathrm{wt} . \%, 7 \mathrm{ml})$ were obtained under microwave reduction $\left(120^{\circ} \mathrm{C}, 10 \mathrm{~min}, 1000 \mathrm{~W}\right)$ in the presence of a triethylamine as reducing agent $\left(\mathrm{N}\left(\mathrm{C}_{2} \mathrm{H}_{5}\right)_{3}, 2 \mathrm{ml}\right)$. The reduced suspensions were again purified three times and finally dispersed in water. The as-made zeolite suspensions before and after reduction are abbreviated as $\mathrm{Ag}^{+}$-EMT 2h, $\mathrm{Ag}^{+}$-EMT $4 \mathrm{~h}$ and $\mathrm{Ag}^{+}$-EMT $6 \mathrm{~h}$ and $\mathrm{Ag}^{0}$-EMT 2h, $\mathrm{Ag}^{0}$-EMT 4h, $\mathrm{Ag}^{0}$-EMT 6h, correspondingly, according to the different ion-exchange time used (2, 4 and 6 hours).

\section{Antibacterial tests}

A single colony of Escherichia coli (E. coli, ATCC 8739) from a freshly cultured nutrient agar (Oxoid, UK) plate was removed using a sterile loop and inoculated in a $100 \mathrm{ml}$ of sterile nutrient broth (Oxoid, UK). Broth was incubated for 18-24 hours at $37{ }^{\circ} \mathrm{C}$ in a rotary shaker incubator set at $150 \mathrm{rpm}$. The liquid culture was centrifuged at $3000 \mathrm{rpm}$ for 10 minutes to form a pellet. The supernatant was discarded and the pellet was resuspended in distilled water. An optical density of 1.0 at 540 $\mathrm{nm}$ wavelength was obtained (Jenway 6305 Spectrophotometer, UK), equalling approximately $10^{8}$ colony-forming units (CFU) per $\mathrm{mL} .25 \mu \mathrm{l}$ of the bacterial suspension was added to $5 \mathrm{ml}$ of $0.5 \mathrm{mg} \mathrm{mL} \mathrm{m}^{-1}$ suspension of $\mathrm{Ag}^{+}$-EMT and $\mathrm{Ag}^{0}$-EMT. Ag-free EMT sample was used for control experiments. The samples were incubated at $37^{\circ} \mathrm{C}$ in a rotary shaker incubator set at 150 rpm and a sample was taken every 60 seconds using a 50 dropper over a period of 0-7 minutes. A single drop $(20 \mu \mathrm{l})$ of sample was added to an eighth of a nutrient agar (Oxoid, UK) or thyoglycolate agar plate for culturing the $E$. coli. The thyoglycollate (thio-neutralizing) agar was prepared by mixing thioglycollate broth with $1.2 \mathrm{wt} \%$ technical agar (Oxoid, UK). All tests were carried out in duplicates. After overnight incubation at $37{ }^{\circ} \mathrm{C}$ the drops were examined for the degree of $E$. coli growth to give an indication of the number of bacteria remaining following exposure to the $\mathrm{Ag}^{+}$-EMT and $\mathrm{Ag}^{0}$-EMT samples.

\section{Characterisation of silver-EMT zeolites}

The structure of EMT zeolite nanocrystals and presence of Ag was confirmed by recording the Powder X-ray Diffraction (XRD) patterns using a PANalytical X'Pert Pro diffractometer with $\mathrm{Cu} \mathrm{K} \alpha$ monochromatized radiation $(\lambda=1.5418 \AA)$. The samples were scanned in the range $4^{\circ}-80^{\circ} 2 \theta$, with a step size of $0.02^{\circ}$. The size and confinement arrangements of $\mathrm{Ag}$ within the zeolite nanocrystals were determined by transmission electron microscopy (TEM) using a FEI Titan 80-300 operating at $300 \mathrm{kV}$. Zeta potential measurements were conducted on the zeolite suspensions in order to confirm the colloidal stability of samples using a Malvern Zetasizer Nano in back scattering mode. The porosity of the EMT and AgEMT samples was probed by measuring the $\mathrm{N}_{2}$ sorption isotherms at $-196{ }^{\circ} \mathrm{C}$ using a Micrometrics ASAP 2020 volumetric adsorption analyzer. Samples were outgassed at $250{ }^{\circ} \mathrm{C}$ under vacuum overnight prior to measurements. Specific surface areas were determined from the BET equation. The t-plot method was used to distinguish the micropores from the mesopores in the samples and to calculate the external surface areas. The mesopore volumes were calculated after subtracting the microporre volume from the total pore volume. The chemical composition of the samples was measured on a Varian Vista AX CCD inductively coupled plasma atomic emission spectrometer (ICP-AES). UV-vis absorption spectra of the silver loaded zeolite suspensions were recorded using a Varian Cary 4000 Spectrophotometer.

\section{Results and discussion}

\section{Silver-EMT zeolites}

EMT zeolite was prepared in the form of colloidal suspension and used in all subsequent procedures, including silver ionexchange, reduction of silver and antibacterial tests. The stability of the Ag-zeolite nanocrystals in the suspensions was characterized by zeta potential measurements. The zeta potential $(\xi)$ of all Ag-EMT samples were below $-40 \mathrm{mV}$, indicating high colloidal stability (ESI, Table S1). The chemical composition of the Ag-EMT zeolite samples is summarized in Table 1. The amount of silver increased from 1 to $14 \mathrm{wt} \%$ with an increase in the ion-exchange time from 2 to $6 \mathrm{~h}$, respectively. This result shows that high silver loading can be achieved within short ion-exchange times. The amount of silver did not change before and after reduction of silver $\left(\mathrm{Ag}^{+}\right.$to $\left.\mathrm{Ag}^{0}\right)$.

Table 1. ICP results of $\mathrm{Ag}^{+}$-EMT and $\mathrm{Ag}^{0}$-EMT samples.

\begin{tabular}{ccccc}
\hline Sample & $\begin{array}{c}\mathrm{Ag} \\
\text { (wt. \%) }\end{array}$ & $\begin{array}{c}\mathrm{Si} \\
\text { (wt. \%) }\end{array}$ & $\begin{array}{c}\mathrm{Al} \\
\text { (wt. \%) }\end{array}$ & $\begin{array}{c}\mathrm{Na} \\
\text { (wt. \%) }\end{array}$ \\
\hline $\mathrm{Ag}^{+}$-EMT 2h & 1.1 & 13.5 & 13.1 & 7.8 \\
$\mathrm{Ag}^{0}$-EMT 2h & 1.2 & 13.1 & 12.9 & 7.5 \\
$\mathrm{Ag}^{+}$-EMT 4h & 8.0 & 13.2 & 12.9 & 5.7 \\
$\mathrm{Ag}^{0}$-EMT 4h & 9.1 & 11.5 & 10.5 & 5.0 \\
$\mathrm{Ag}^{+}$-EMT 6h & 14.0 & 11.1 & 10.8 & 2.7 \\
$\mathrm{Ag}^{0}$-EMT 6h & 14.1 & 11.3 & 10.2 & 2.2 \\
\hline
\end{tabular}

The crystallinity of the pure EMT and silver containing zeolite samples before and after microwave reduction was characterized by XRD (Fig. 1). All samples show the diffraction peaks characteristic of highly crystalline EMT-type zeolite, however a broadening of the peaks is observed due to the ultrasmall size of the zeolite particles $(10-20 \mathrm{~nm})$ (Fig. 1a). No Bragg peaks corresponding to metallic silver in the ionexchanged samples $\left(\mathrm{Ag}^{+}\right.$-EMT $2 \mathrm{~h}, \mathrm{Ag}^{+}$-EMT $4 \mathrm{~h}$ and $\mathrm{Ag}^{+}$-EMT $6 \mathrm{~h})$ are seen. However, a weak Bragg peak corresponding to the silver metal at $38.2^{\circ}$ (111) appeared in sample $\mathrm{Ag}^{0}$-EMT $6 \mathrm{~h}$. 
Moreover, the diffraction peaks of EMT shifted to smaller twotheta angle as shown in the inset of Fig. 1a with progressive exchange of $\mathrm{Na}^{+}$for $\mathrm{Ag}^{+}$. This shift can be explained by the larger ionic radius of $\mathrm{Ag}^{+}(0.115 \mathrm{~nm})$ compared to that of $\mathrm{Na}^{+}$ $(0.098 \mathrm{~nm})$.

The size and location of the Ag NPs are further studied by HRTEM. Fig. 2 shows representative high-resolution TEM images of Ag NPs supported on EMT zeolites prepared at different ion-exchange times. The crystalline fringes associated with the EMT lattice appear clearly in the three samples (Fig. 2). Moreover, the presence of mono-dispersed Ag NPs confined within the EMT zeolite, i.e., predominantly located in the sodalite cages, can be seen in samples $\mathrm{Ag}^{0}$-EMT $2 \mathrm{~h}$ and $\mathrm{Ag}^{0}$ EMT $4 \mathrm{~h}$. The size of the Ag NPs in the sodalite cages is about $0.6 \mathrm{~nm}$ (Fig. $2 \mathrm{~b}, \mathrm{~d}$ ). In sample $\mathrm{Ag}^{0}$-EMT $6 \mathrm{~h}$, the amount of silver is considerably higher, leading to partial leakage from the zeolite matrix and to formation of larger Ag NPs with a size of 2-5 $\mathrm{nm}$. The large Ag NPs are predominantly located on the surface of the zeolite crystals as shown in Fig. 2 e,f. The number of these Ag NPs on the surface of the zeolites increased from sample $\mathrm{Ag}^{0}$-EMT $4 \mathrm{~h}$ to $\mathrm{Ag}^{0}$-EMT 6h, however in both cases they are strongly attached to the zeolite.
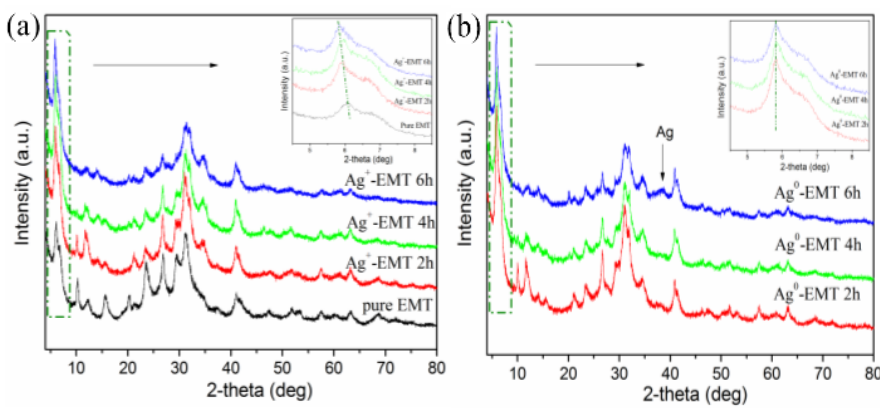

Fig. 1 XRD patterns of (a) pure EMT and $\mathrm{Ag}^{+}$-EMT $2 \mathrm{~h}, 4 \mathrm{~h}$ and $6 \mathrm{~h}$ and (b) $\mathrm{Ag}^{0}$ EMT $2 \mathrm{~h}, 4 \mathrm{~h}$ and $6 \mathrm{~h}$ samples.

The pore structure of EMT-zeolite before and after silver confinement was studied by nitrogen adsorption (Fig. 3). Nitrogen adsorption isotherms showed a high gas uptake at low relative pressures, characteristic for microporous materials. A hysteresis loop was present at high relative pressures, which could be associated with the small particle size of the zeolite crystals. $^{20}$ The micropore volume of Ag-exchanged EMT samples decreased compared to pure EMT-zeolite (Table 2). This is also consistent with the larger ionic radius of $\mathrm{Ag}^{+}$ compared to that of $\mathrm{Na}^{+}$. Moreover, the micropore volume was slightly lower for the reduced $\mathrm{Ag}^{0}$-EMT samples. The specific surface area and external surface area of the samples decreased as well with increasing the amount of $\mathrm{Ag}$ confined within the zeolite. At the same time, the interparticle mesopore volume of $\mathrm{Ag}^{0}$-EMT samples was higher compared to $\mathrm{Ag}^{+}$-EMT samples. The nitrogen adsorption isotherms (Fig. 3) and mesopore size distributions (ESI, Fig. S1) indicated that there were small variations in the textural porosity of Ag-EMT samples. These changes in the pore structure characteristics agree well with the XRD and TEM data.

The UV-vis absorption spectra of silver containing EMT samples are shown in Fig. 4. The spectra of $\mathrm{Ag}^{+}$-EMT 2, 4, and $6 \mathrm{~h}$ samples show no absorption in the range from 200 to 800 $\mathrm{nm}$. After microwave reduction (samples $\mathrm{Ag}^{0}$-EMT 2, 4, and 6 h), a plasmon band at $400 \mathrm{~nm}$ appears that corresponds to the formation of $\mathrm{Ag}$ NPs. The intensity of the plasmon band in sample $\mathrm{Ag}^{0}$-EMT $6 \mathrm{~h}$ is the highest, which is explained with the presence of Ag NPs with a size of 2-5 nm predominantly located on the surface of the EMT zeolite. These results are coherent with the XRD and TEM observations (Figs. 1 and 2).
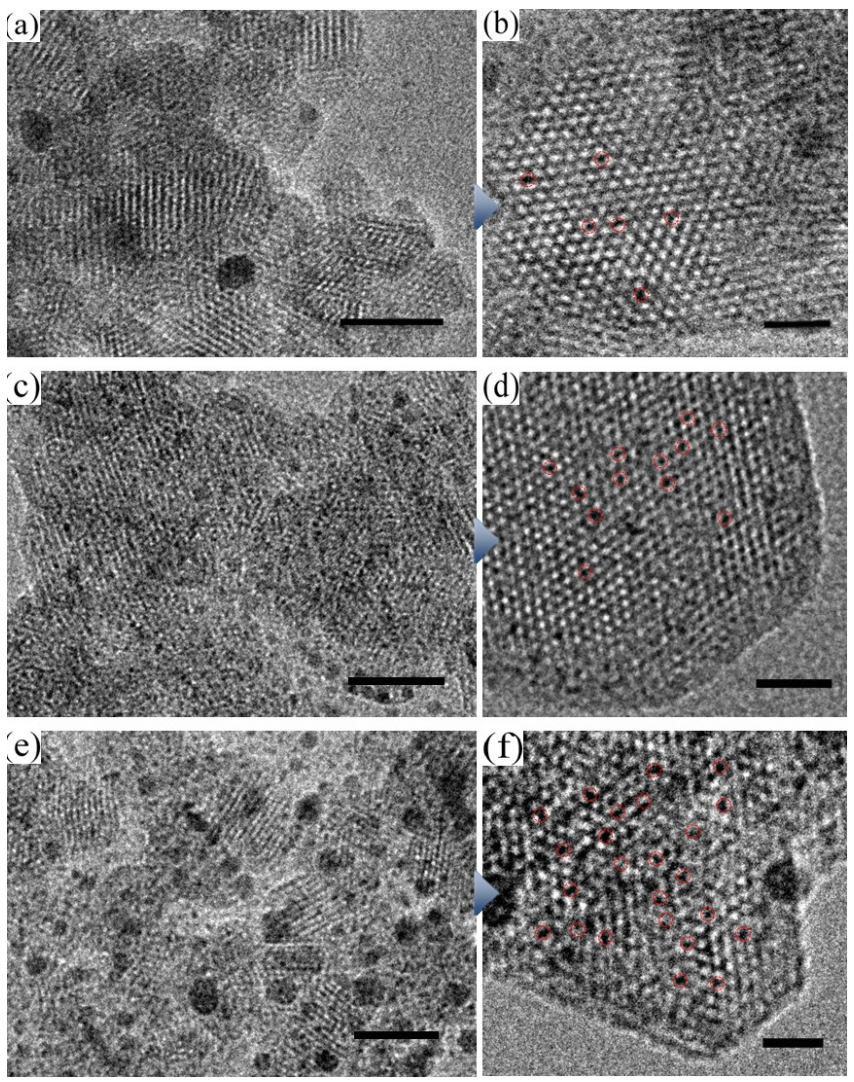

Fig. 2 TEM images of (a, b) $\mathrm{Ag}^{+}$-EMT 2h, (c,d) $\mathrm{Ag}^{+}$-EMT 4h, and (e,f) $\mathrm{Ag}^{+}$-EMT 6h samples. Scale bar $\mathrm{M}=20 \mathrm{~nm}(\mathrm{a}, \mathrm{c}, \mathrm{e})$; Scale bar $\mathrm{M}=2 \mathrm{~nm}(\mathrm{~b}, \mathrm{~d}, \mathrm{f})$.
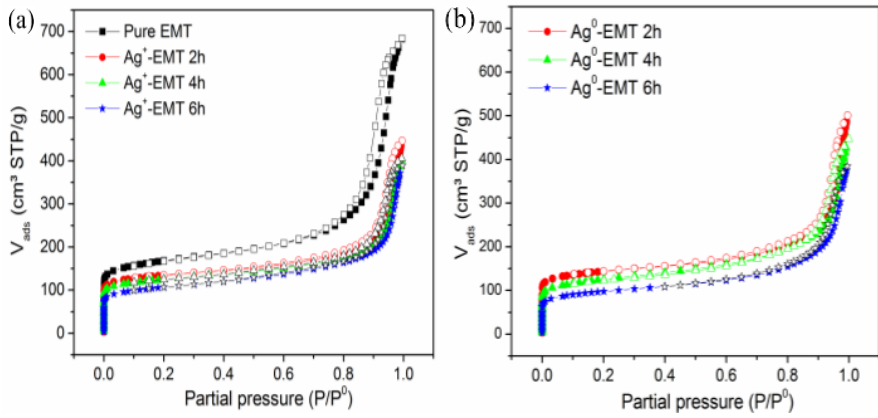

Fig. 3 Nitrogen sorption isotherms of (a) pure EMT and $\mathrm{Ag}^{+}$-EMT 2, 4 and 6 h, and (b) $\mathrm{Ag}^{0}$-EMT 2, 4, and $6 \mathrm{~h}$ samples.

Table 2 Gas adsorption data for $\mathrm{Ag}^{+}$-EMT and $\mathrm{Ag}^{0}$-EMT samples

\begin{tabular}{ccccc}
\hline Sample & $\begin{array}{c}\mathrm{S}_{\mathrm{BET}^{\mathrm{a}}} \\
\left(\mathrm{m}^{2} \mathrm{~g}^{-1}\right)\end{array}$ & $\begin{array}{c}\mathrm{V}_{\text {mic }^{\mathrm{b}}} \\
\left(\mathrm{cm}^{3} \mathrm{~g}^{-1}\right)\end{array}$ & $\begin{array}{c}\mathrm{S}_{\text {ext }}{ }^{\mathrm{c}} \\
\left(\mathrm{m}^{2} \mathrm{~g}^{-1}\right)\end{array}$ & $\begin{array}{c}\mathrm{V}_{\text {meso }}{ }^{\mathrm{d}} \\
\left(\mathrm{cm}^{3} \mathrm{~g}^{-1}\right)\end{array}$ \\
\hline Pure EMT & 592 & 0.17 & 201 & 0.70 \\
$\mathrm{Ag}^{+}$-EMT 2h & 487 & 0.15 & 127 & 0.36 \\
$\mathrm{Ag}^{0}$-EMT 2h & 517 & 0.16 & 136 & 0.42 \\
$\mathrm{Ag}^{+}$-EMT 4h & 447 & 0.13 & 135 & 0.35 \\
$\mathrm{Ag}^{0}$-EMT 4h & 425 & 0.12 & 173 & 0.42 \\
$\mathrm{Ag}^{+}$-EMT 6h & 366 & 0.10 & 151 & 0.38 \\
$\mathrm{Ag}^{0}$-EMT 6h & 326 & 0.09 & 130 & 0.39 \\
\hline
\end{tabular}

${ }^{\text {a }}$ SBET: $_{\text {: specific surface area; }}{ }^{b} \mathrm{~V}_{\text {mic }}$ : micropore volume, ${ }^{c} S_{\text {ext }}$ : external surface area, $\mathrm{V}_{\text {meso }}$ : mesopore volume. 

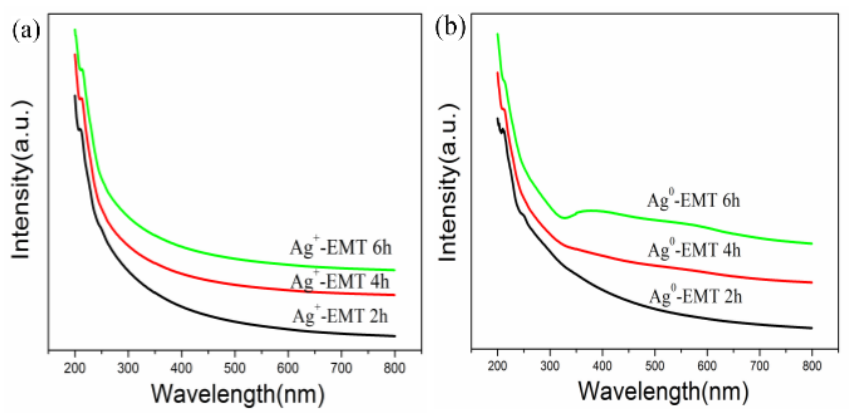

Fig. 4 UV-Vis spectra of (a) $\mathrm{Ag}^{+}$-EMT 2, 4 and $6 \mathrm{~h}$ and (b) $\mathrm{Ag}^{0}$-EMT 2, 4, and $6 \mathrm{~h}$ samples.

\section{Antibacterial properties of silver-EMT zeolites}

The bacterium selected in this study for determination of the antimicrobial properties of Ag-EMT samples was E. coli as one of the most studied microorganisms in Ag-zeolite works. ${ }^{11-18}$ The zeolite concentrations used in the tests were based on our previous work on Ag-FAU zeolites. ${ }^{21}$ The aim of the experiments was to directly compare the killing efficacy of $\mathrm{Ag}^{+}$-EMT and $\mathrm{Ag}^{0}$-EMT samples. Thus, a qualitative evaluation rather than quantitative measurements was performed. Experiments with Ag-free EMT zeolite (control) using both nutrient agar and thio-neutralizing agar indicated that the number of viable $E$. coli cells was unaffected independently of the growth medium used (Fig. 5). In the presence of the Ag-containing EMT zeolite, initial experiments were conducted using nutrient agar as the growth medium for $E$. coli. However no viable cells were detected from any of the Ag-containing EMT samples (Fig. 6), even after sampling immediately following the addition of $E$. coli to the Agcontaining samples $(0 \mathrm{~min})$. Further experiments continued using a thioglycollate agar in order to neutralize the effects of the Ag. ${ }^{22,23}$

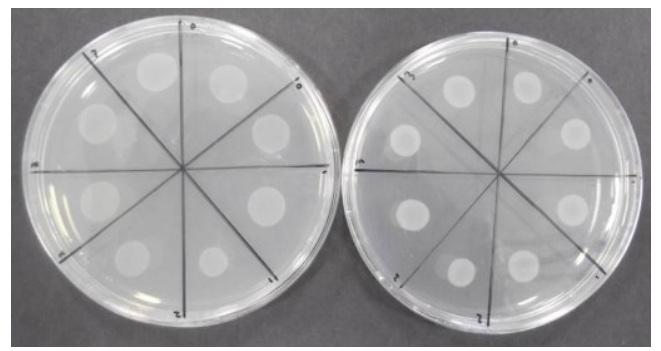

Fig. 5 Spot inoculation of E. coli (in duplicates) onto thio-neutralizing agar (left) and nutrient agar (right) at 1 minute intervals, following exposure to Ag-free EMT zeolite Control). Each drawn slice corresponds to one minute sampling time; the first sample is taken directly after mixing $(0 \mathrm{~min})$.

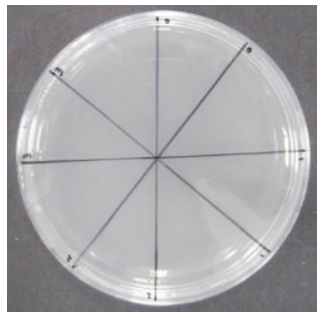

Fig. 6 Spot inoculation of E. coli (in duplicates) onto nutrient agar plates at 1minute intervals, following exposure to $\mathrm{Ag}^{+}$-EMT and $\mathrm{Ag}^{0}$-EMT zeolite samples. Each drawn slice corresponds to one minute sampling time; the first sample is taken directly after mixing $(0 \mathrm{~min})$.

In the presence of $\mathrm{Ag}^{+}$-EMT $4 \mathrm{~h}$ and $\mathrm{Ag}^{+}$-EMT $6 \mathrm{~h}$ samples, the number of viable $E$. coli cells visually decreased over time and no viable cells were detected at 3 and 1 minutes of incubation, respectively (Fig. 7, left). For the $\mathrm{Ag}^{0}$-EMT $4 \mathrm{~h}$ and $6 \mathrm{~h}$ samples respectively, no viable E.coli was seen at 2- and 1minute, respectively (Fig. 7 , right). The approximate killing times increased to $6 \mathrm{~min}$ in the presence of $\mathrm{Ag}^{+}$-EMT $2 \mathrm{~h}$ samples (ESI).

The antibacterial experiments performed indicated that: (i) the use of a neutralizing agar for halting continuation of Ag action on bacteria following exposure time was of great importance for the results obtained, which one more time emphasized the difficulty in comparing results from different studies because of the different test conditions used; ${ }^{4,11-18}$ (ii) the killing efficacy increased with increasing $\mathrm{Ag}$ content in agreement with previous studies; ${ }^{6}$ and (iii) $\mathrm{Ag}^{0}$-EMT samples were slightly more active compared to $\mathrm{Ag}^{+}$-EMT samples across the different $\mathrm{Ag}$ loadings used in this work. The latter observation is surprising considering that the antibacterial properties of $\mathrm{Ag}^{0}$ are associated to its oxidation to $\mathrm{Ag}^{+}$in aqueous environment. ${ }^{4,10}$ Possible explanations for these results could be the increased amount of surface silver NPs in Ag0EMT samples combined with the higher interparticle mesopore volume (Table 2). As a result an improved Ag mobility resulting in higher $\mathrm{Ag}^{+}$concentration in solution is achieved. Nevertheless, the difference in the killing times for reduced and non-reduced silver in the EMT samples was not significant. The results indicated an instant killing of $E$. coli upon exposure to $\mathrm{Ag}^{+}$-EMT and $\mathrm{Ag}^{0}$-EMT $6 \mathrm{~h}$ zeolite suspensions demonstrating the potential of these materials for antibacterial applications.

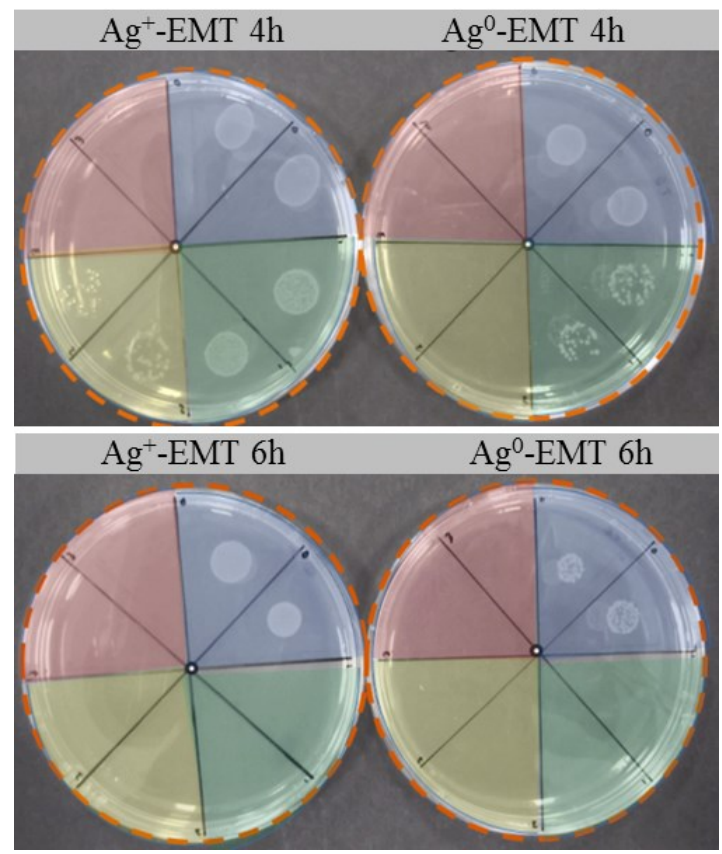

Fig. 7 Spot inoculation of E. coli onto thioglycollate agar plates (in duplicate) following 1-minute interval exposure to $\mathrm{Ag}^{+}$-EMT and $\mathrm{Ag}^{0}$-EMT zeolite samples. Each drawn slice above corresponds to one minute sampling time; the first sample is taken directly after mixing $(0 \mathrm{~min})$. 


\section{Conclusions}

The syntheses of ultrasmall EMT-type zeolite suspensions containing silver cations and silver nanoparticles are reported. High loading of silver in the template-free EMT zeolite nanocrystals is achieved by ion-exchange process carried out for short times $(2,4$ and $6 \mathrm{~h})$. Subsequently, the microwave reduction of silver cations to silver nanoparticles in the presence of reducing agent (triethylammine) is accomplished. The EMT zeolite nanocrystals with high silver content show excellent antimicrobial activity against Escherichia coli. The $\mathrm{Ag}^{0}$-EMT (2, 4 and $\left.6 \mathrm{~h}\right)$ samples show slightly better antimicrobial efficacy compared to that of $\mathrm{Ag}^{+}$-EMT (2, 4 and 6 h) analogue samples due to increased mesoporosity. However, the differences are not significant and reduction of ionexchanged $\mathrm{Ag}^{+}$within the zeolite to $\mathrm{Ag}$ nanoparticles is not viable considering the complexity of preparation steps. The results in the study demonstrate that $E$. coli cells are instantly killed upon exposure to water suspensions of ultrasmall $\mathrm{Ag}^{+}$EMT and $\mathrm{Ag}^{0}$-EMT $6 \mathrm{~h}$ zeolites. Antibacterial tests also showed that neutralizing $\mathrm{Ag}$ to halt $\mathrm{Ag}$ activity following incubation with microorganisms is essential for the reliabilities of the tests.

\section{Acknowledgements}

The financial support from the FFCSA and Total is acknowledged.

\section{Notes and references}

${ }^{a}$ Laboratoire Catalyse \& Spectrochimie, University of Caen, CNRS, 6, boulevard du Maréchal Juin, 14050 Caen Cedex, France. E-mail: svetlana.mintova@ensicaen.fr

${ }^{b}$ State Key Laboratory on Integrated Optoelectronics, College of Electronic Science and Engineering, Jilin University, Changchun 130012, P. R. China.

c Faculty of Science and Engineering, Manchester Metropolitan University, Chester St., Manchester, M1 5GD, UK. E-mail: 1.tosheva@mmu.ac.uk

${ }^{d}$ CRISMAT, ENSICAEN, University of Caen, 6, boulevard du Maréchal Juin, 14050 Caen Cedex, France.

Electronic Supplementary Information (ESI) available: Zeta potential data of Ag-EMT suspensions, pore-size distributions and antibacterial data for Ag-EMT 2h samples. See DOI: 10.1039/b000000x/

1 A. Muñoz-Bonilla and M. Fernández-García, Prog. Polym. Sci., 2012, 37, 281.

2 D. Campoccia, L. Montanaro and C. R. Arciola, Biomater., 2013, 34, 8533.

3 S. Chernousova and M. Epple, Angew. Chem. Int. Ed., 2013, 52, 1636.

4 L. Rizzello and P. P. Pompa, Chem. Soc. Rev., 2014, 43, 1501.

5 Q. L. Feng, J. Wu, G. O. Chen, F. Z. Cui,T. N. Kim. and J. O. Kim, J. Biol. Mater. Res., 2000, 52, 662.

6 I. Sondi and B. Salopek-Sondi, J. Colloid Interf. Sci., 2004, 275, 177.

7 J. R. Morones, J. L. Elechiguerra, A. Camacho, K. Holt, J. B. Kouri, J. T. Ramírez and M. J. Yacaman, Nanotechnology, 2005, 16,2346.

8 C.-N. Lok, C.-M. Ho, R. Chen, Q.-Y. He, W.-Y. Yu, H. Sun, P. K.-H. Tam, J.-F. Chiu and C.-M. Che, J. Biol. Inorg. Chem., 2007, 12, 527.

9 O. Choi, K. K. Deng, N.-J. Kim, L. Ross Jr. and R. Y. Surampalli, Water. Res., 2008, 42, 3066.
10 Z. Xiu, Q. Zhang, H. L. Puppala, V. L. Colvin and P. J. J. Alvarez, Nano Lett., 2012, 12, 4271.

11 Y. Zhou, Y. Deng, P. He, F. Dong, Y. Xia and Y. He, RSC Advances, 2014, 4, 5283.

12 Y. Matsumura, K. Yoshikata, S. Kunisaki and T. Tsuchido, Appl. Environ. Microbiol., 2003, 69, 4278.

13 C. Carolina, B. Juan Carlos, B. M. L. Zapata and Z. Juan Manuel, Microporous Mesoporous Mater., 2014, 188, 118.

14 P. Lalueza, M. Monzón, M. Arruebo and J. Santamaría, Mater. Res. Bull., 2011, 46, 2070.

15 P. Saint-Cricq, Y. Kamimura, K. Itabashi, A. Sugawara-Narutaki, A. Shimojima and T. Okubo, Eur. J. Inorg. Chem., 2012, 3398.

16 L. Ferreira, A. M. Fonseca, G. Botelho, C. Almeida-Aguiar and I. C. Neves, Microporous Mesoporous Mater., 2012, 160, 126.

17 S. Sabbani, D. Gallego-Perez, A. Nagy, W. J. Waldman, Derek Hansford and P. K. Dutta, Microporous Mesoporous Mater., 2010, 135, 131.

18 R. Guerra, E. Lima, M. Viniegra, A. Guzmán and V. Lara, Microporous Mesoporous Mater., 2012, 147, 267.

19 E.-P. Ng, D. Chateigner, T. Bein, V. Valtchev, S. Mintova. Science, 2012, 335, 70 .

20 W. Song, R. E. Justice, C. A. Jones, V. H. Grassian, and S. C. Larsen, Langmuir, 2004, 20, 8301.

21 L. Tosheva, A. Brockbank, B. Mihailova, J. Sutula, J. Ludwig, H. Potgieter and J. Verran. J. Mater. Chem., 2012, 22, 16897.

22 R. C. Tilton and B. Rosenberg, Appl. Environ. Microbiology, 1978, 35, 1116.

23 S. Y. Liau, D. C. Read, W. J. Pugh, J. R. Furr, and A. D. Russel, Lett. Appl. Microbiol., 1997, 25, 279. 